\title{
Kent Lojistiği Alanındaki Yayınların Bibliyometrik Analizi
}

\author{
Bibliometric Analysis Of Publications In The Field Of City Logistics
}

\author{
Ramazan ERTURGUT* \\ Hasan Emin GÜRLER***
}

\begin{abstract}
$\ddot{O} Z$
Dünya çapında nüfusun büyük bir çoğunluğu şehirlerde yaşadĭ̆ından dolayı insanların yaşam kalitelerinin arttırılmasında, kent ekonomilerinin kalkınmasında ve küresel tedarik zincirlerinin etkinliğinde şehir lojistiğinin önemli bir etkisi vardır. Özellikle yük taşımacılı̆̆ındaki değişimler ve e-ticaretin yaygınlaşması ile birlikte şehir lojistiğinin etkinliği daha da önemli bir olgu haline gelmiştir. Söz konusu gelişmelerin önemli bir sonucu olarak şehirlerde insan yaşamını olumsuz etkileyecek düzeyde hava kirliliği artmakta, trafik sıkışıklıkları ve kazaları meydana gelmekte, yerel yönetimlerin şehir lojistiğine ilişkin stratejileri sekteye uğramakta ve çevresel kaygllar yaşanmaktadır. Bu durum ve yaşanan buna benzer sorunlar, politikacıların ve şehir lojistiğine ilgi duyan araştırmacıların dikkatini çekmiştir. Özellikle son on yılda şehir lojistiğine yönelik araştırmaların sayısı önemli ölçüde artmıştır. Bu nedenle bu çalışmada; 1970-2019 yılları arasında şehir lojistiği alanında yapılan araştırmaları bibliyometrik analiz yöntemi yardımıyla incelemek ve akademik yazında şehir lojistiğine ilişkin araştırmaların hangi doğrultuda ilerlediğini ortaya koymak amaçlanmıştır. Bu amaç doğrultusunda Web of Science veritabanında şehir lojistiği kavramı kullanılarak tarama yapılmış ve toplamda 680 yayına ulaşılmıştır. Yayınlar, bibliyometrik analiz yöntemi ile incelenmiştir. Sonuç olarak; en fazla kullanılan iki anahtar

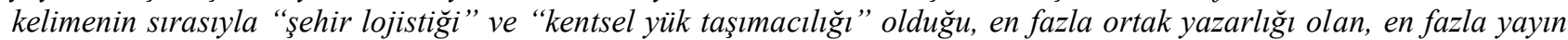
yapan ve en fazla atıf alan araştırmacının E. Taniguchi olduğu, en fazla yayın yapan ve en fazla atı alan ülkenin İtalya olduğu ve en fazla yayının 2016 yılında yapıldı̆̆ tespit edilmiştir.
\end{abstract}

\section{ANAHTAR KELIMELER}

Şehir Lojistiği, Bibliyometrik Analiz, Literatür İncelemesi

\begin{abstract}
Since the vast majority of the world's population lives in cities, city logistics has a significant impact on improving people's quality of life, on the development of urban economies, and on the effectiveness of global supply chains. Especially with the changes in freight transportation and the spread of e-commerce, the effectiveness of city logistics has become an even more important phenomenon. As a consequence of these developments, air pollution is increasing in cities at a level that affects people's lives negatively, traffic jams and accidents are occurring, the strategies of local governments regarding city logistics are interrupted and environmental concerns are experienced. This situation and similar problems have attracted the attention of politicians and researchers interested in urban logistics. Especially in the last decade, the number of studies on urban logistics has increased significantly. For this reason, in this study, it is aimed to examine the researches conducted in the field of city logistics between 1970 and 2019 with the help of bibliometric analysis method and to show the direction of the researches about city logistics in academic literature. For this purpose, the Web of Science database was searched using the topic of city logistics and a total of 680 publications were reached. The publications were examined by bibliometric analysis method. As a result, it was found that the two most commonly used keywords were "city logistics" and "urban freight transport" respectively; E. Taniguchi is the author with the most coauthorship, the highest number of publications and the most cited researchers; Italy was the country with the highest number of publications and the highest number of citations, and that the highest number of publications was made in 2016.
\end{abstract}

KEYWORDS

City Logistics, Bibliometric Analysis, Literature Review

\begin{tabular}{|c|c|c|}
\hline \multicolumn{2}{|c|}{ Makale Geliş Tarihi / Submission Date } & \multicolumn{1}{c|}{$\begin{array}{c}\text { Makale Kabul Tarihi / Date of Acceptance } \\
\text { 25.07.2019 }\end{array}$} \\
\hline \multirow{3}{*}{ Atıf } & $\begin{array}{l}\text { Erturgut, R. ve Gürler, H. E. (2019). Kent Lojistiği Alanındaki Yayınların Bibliyometrik Analizi. Selçuk Üniversitesi } \\
\text { Sosyal Bilimler Meslek Yüksekokulu Dergisi, 22 (2), 540-551. }\end{array}$ \\
\hline
\end{tabular}

\footnotetext{
* Prof. Dr., Akdeniz Üniversitesi Uygulamalı Bilimler Fakültesi, rerturgut@ akdeniz.edu.tr, ORCID: 0000-0002-0240-5787

** Arş. Gör., Akdeniz Üniversitesi Uygulamalı Bilimler Fakültesi, hasangurler@akdeniz.edu.tr, ORCID: 0000-0002-5813-1631
} 


\section{GİRIŞ}

Şehir lojistiği, taşımacılık faaliyetlerini optimize etmek ve kentsel alanların sürdürülebilir kalkınmasını desteklemek için bir stratejidir (Kaur ve Awasthi, 2018: 162). Şehir lojistiği, şehirlerin ekonomik kalkınmasında, sosyal ve çevresel konuların uyum içinde olması bakımından önemli bir rol oynamaktadır. İnsanların sosyal, kültürel faaliyetleri ve şirketlerin ekonomik faaliyetleri için temel yapıyı oluşturmaktadır (Kaur ve Awasthi, 2018: 161). Şehir lojistiği, kentsel alanlarda tedarikçiler ve tüketiciler arasında büyük ölçekli yük taşımacılığı faaliyetlerinin sürekli ve istikrarlı bir şekilde yürütülmesini sağlamaktadır. Ayrıca şehir lojistiği; tedarik zincirlerinin etkinliği ve istihdam olanakları açısından büyük önem arz etmektedir. Eticaretin yaygınlaşması ve kentsel tüketim kapasitesinin arttırılması ile birlikte kentsel dăğtım hizmetlerine olan talep hızla artmıştır. Bu artış ise şehirlerde tıkanıklığa, düşük düzeyde erişilebilirliğe, verimsizliğe, sera gazı emisyonunun artmasına, kaynak israfının artmasına, gürültüye, halk sağlığının bozulmasına, kazalara ve yerel yönetimler açısından birtakım olumsuzluklara neden olmaktadır (Hu ve diğ., 2019: 1). Şehirdeki atmosferik kirlenmelerin ve trafik tehlikelerinin \%40'ından fazlası şehir lojistiğinden kaynaklanmaktadır. Açıkçası, şehir lojistiği sorunları; insan sağlığını ve yaşam kalitesini önemli ölçüde olumsuz etkilemektedir (Hu ve diğ., 2019: 1-2).

Kentsel bölgelerde yaşayan nüfusun sürekli olarak artması, şehirlerde kirlilik ve güvenlik kaygıları, trafik ve trafik sıkışıklığı sorunları ve yeni mevcut teknolojik firsatlar, politika yapıcıların ve kent lojistiği olgusuna ilgi duyan araştırmacıların dikkatini çekmiştir (Lagorio ve dĭğ., 2016: 908). Son yıllarda, özellikle şehirdeki ekonomik büyümeye ilişkin artan katkısı ve çevreye yönelik taşımacılık kaynaklı emisyonlar nedeniyle şehir lojistiğine yönelik çalışmaların sayısında bir artış olmuştur (Kaur ve Awasthi, 2018: 161). Şehir lojistiği özellikle son on yılda önem kazanan bir ilgi alanı olmuştur ve araştırmacılar arasında popülerlik kazanmıştır (Kaur ve Awasthi, 2018: 162). Söz konusu bu önemli artışa ve popülerliğe rağmen literatürde şehir lojistiğine ilişkin olarak 1970-2019 yılları arasında yapılmış olan araştırmaları bibliyometrik analiz yöntemini kullanarak inceleyen çalışma bulunmamaktadır. Bu nedenle bu çalışmada; 1970-2019 yılları arasında şehir lojistiği alanında yapılan araştırmaları bibliyometrik analiz yöntemi yardımıyla incelemek ve akademik yazında şehir lojistiğine ilişkin araştırmaların hangi doğrultuda ilerlediğini ortaya koymak amaçlanmıştır.

\section{LITERATÜR}

\subsection{Kent (Şehir) Lojistiği}

Kent lojistiği; kentsel alanlarda özel şirketler tarafindan yapılan lojistik ve taşımacılık faaliyetlerinin trafik çevresi, trafik sıkışıklığı ve enerji tüketimi gibi olgular göz önünde bulundurularak optimize edilmesi sürecidir. Şehir lojistiğinin temelinde, şehir içinde gerçekleştirilen mal dağıtımlarına ilişkin çözümler sunmak yer almaktadır. Şehir lojistiği; ilgili paydaşlar arasında entegrasyon ve koordinasyonu göz önünde bulundurarak, büyük bir şehirde ve lojistik bir ağ içinde gerçekleştirilen yük hareketlerini optimum şekilde planlamay1, yönetmeyi ve kontrol etmeyi amaçlamaktadır (Neghabadi ve diğ., 2019: 866). Bununla birlikte şehir lojistiğinin üç temel hedefi bulunmaktadır: (1) yaşam kalitesini iyileştirmek, (2) insan ve yük akışını iyileştirmek, (3) çevreyi korumak. Bu hedeflerin gerçekleştirilmesi, şehir lojistiği konusunda farklı beklentileri olan üreticiler, taşıyıcılar, depolama firmaları, perakendeciler, toptancılar, müşteriler, ulusal ve bölgesel idareler gibi birçok paydaşın katılımını içermektedir (Hajduk, 2017: 283).

Şehir lojistiği, şehir yönetimi alanında önemi gittikçe artan bir konu olmuştur. Şehir nüfusları sürekli bir şekilde artmakta ve bu durum altyapıya erişimi daha zor hale getirmekte ve sonuç olarak yaşam kalitesini düşürmektedir (Hajduk, 2017: 283). Bugün dünya nüfusunun \%55'i şehirlerde yaşamaktadır. 2050 yılında bu oranın \%68'e yükselmesi beklenmektedir (https://population.un.org, Erişim Tarihi: 25.03.2019). Bununla birlikte hem yolcu hem de yük taşımacılığına ilişkin trafik artmakta ve bu durum trafik sıkışıklığına ve hava kirliliğine neden olmaktadır. Avrupa Komisyonu'nun tahminlerine göre; 2005 yılına kıyasla yük taşımacılığ1 yoğunluğu 2050 yılına kadar \%80'den, yolcu taşımacılığı ise \%50'den fazla artacaktır (Hajduk, 2017: 283). Söz konusu bu problemlere çözüm getirmek adına gelişmiş bilgi sistemleri, ortak yük taşıma sistemleri, kamu lojistik terminalleri, yük faktörü denetimi ve yer altı yük taşıma sistemleri gibi şehir lojistiği girişimleri geliştirilmiştir (Taniguchi ve Van Der Heijden, 2000: 65).

Kent lojistiğine dahil olan dört önemli paydaş bulunmaktadır. Bu paydaşların her birinin kendine özgü amaçları vardır ve her biri farklı şekilde davranma eğilimindedir. Bu nedenle şehir lojistiğine ilişkin modeller geliştiren herkesin bu paydaşları iyi tanıması gerekmektedir. Söz konusu bu paydaşlar Şekil 2.1'de gösterilmiştir (Taniguchi ve diğ., 2001: 3). 


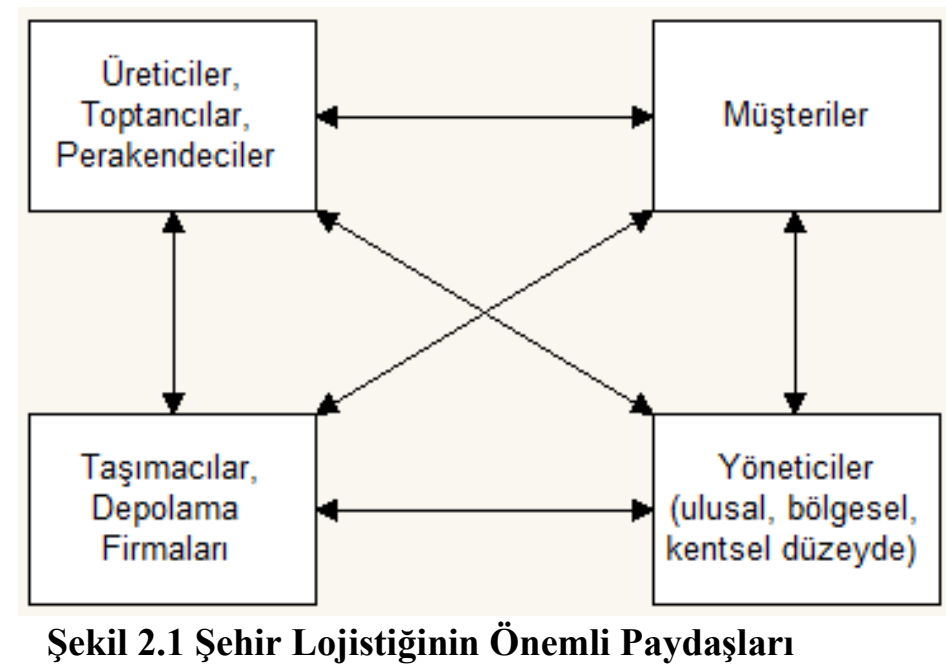

Üreticiler, toptancılar ve perakendeciler, insanlara veya diğer şirketlere ürün gönderen veya onlardan ürün alan taşımacıların, depolama firmalarının müşterileridir. Üreticiler, toptancılar ve perakendeciler genellikle maliyeti, teslim alma veya teslim etme süresini ve nakliye bilgilerinin yanı sıra nakliye güvenilirliğini içeren hizmet düzeylerini en üst düzeye çıkarma eğilimindedirler (Taniguchi ve diğ., 2001: 3). Taşımacılar ve depolama firmaları, genellikle karlarını en üst düzeye çıkarmak için ürün teslimatıyla ilgili maliyetleri en aza indirmeye çalışmaktadırlar. Müşterilere daha düşük toplam maliyetle daha yüksek düzeyde hizmet sağlama konusunda aşırı baskı yaşayan paydaştır. Müşteriler, şehirde yaşayan, çalışan ve alışveriş yapan insanlardır. Trafik sıkışıklığının, gürültünün, hava kirliliğinin ve trafik kazalarının minimum düzeyde olmasını isteyen paydaştır. Şehir yöneticileri, kentin ekonomik gelişimini ve istihdam olanaklarını artırmaya çalışmaktadır. Ayrıca, trafik sıkışıklığını hafifletmeyi, çevresel iyileştirmeler yapmayı ve şehir içindeki karayolu güvenliğini arttırmayı hedeflemektedir (Taniguchi ve diğ., 2001: 4).

Literatürde şehir lojistiğine ilişkin yapılmış olan yayınlar bulunmaktadır. Tablo 2.1'de şehir lojistiği ile ilgili yapılmış olan önceki araştırmalar yer almaktadır. Tablo incelendiğinde; Wolpert ve Reuter'ın (2012) ilk çıktığı günden 2012 yılına kadar olan periyottaki yayınları, Lagorio ve arkadaşlarının (2016) 2000-2015 yılları arasındaki yayınları, Hajduk'un (2017) 1975-2015 yılları arasındaki yayınları, Neghabadi ve arkadaşlarının (2019) ise 2010-2016 yılları arasındaki yayınları incelediği anlaşılmaktadır. Wolpert ve Reuter (2012) Science Direct ve Google Scholar veritabanlarındaki yayınları, Lagorio ve arkadaşları (2016) Elsevier, Science Direct, Emerald, Springer, Wiley Online Library veritabanlarındaki yayınları, Hajduk (2017) Web of Science, Scopus, Elsevier, Emerald ve EBSCO veritabanlarındaki yayınları, Neghabadi ve arkadaşları (2019) ise Science Direct, Web of Science, Google Scholar, Wiley Online Library, Informs ve Springer veritabanlarındaki yayınları incelemiş̧lerdir. Söz konusu çalışmalarda incelenen yayınlar, 2016 y1lı ve öncesinde yayınlanmış olan yayınlardır. Dolayısıyla 2016 yılı sonrasında yayınlanan şehir lojistiği konulu araştırmaları bibliyometrik analiz yöntemini kullanarak inceleyen bir çalışma bulunmamaktadır. Bu çalışma ile birlikte 1970 yılından 2019 yılının mart ayına kadar yapılmış olan ve Web of Science veritabanında yer alan yayınlar incelenmiştir. 
Tablo 2.1 Şehir Lojistiği İle İlgili Önceki Araştırmalar

\begin{tabular}{|c|c|c|}
\hline Araştırmacı & Kapsam & Yöntem \\
\hline Wolpert ve Reuter, 2012 & $\infty-2012$ y1lları aras1, 92 yayın & Sistematik literatür taraması \\
\hline Lindholm, 2013 & 1998-2012 yılları arası, 346 yayın & Derleme \\
\hline Behrends, 2016 & 2009-2013 yılları arası, 150 yayın & Derleme \\
\hline Lagorio vd., 2016 & 2000-2015 yılları arası, 104 yayın & Sistematik literatür taraması \\
\hline Neghabadi vd., 2016 & 2010-2016 yılları arası, 200 yayın & Bibliyometrik analiz \\
\hline Hajduk, 2017 & 1975-2015 yılları arası, 1723 yayın & Bibliyometrik analiz \\
\hline Kaur ve Awasthi, 2018 & 2010-2016 yılları arası, 519 yayın & Bibliyometrik analiz \\
\hline Neghabadi vd., 2019 & 2010-2016 yılları arası, 370 yayın & $\begin{array}{c}\text { Bibliyometrik analiz, sistematik } \\
\text { literatür taraması }\end{array}$ \\
\hline Hu vd., 2019 & 1993-2018 yılları arası, 513 yayın & Bilimmetri (Scientometrics) analizi \\
\hline Savrun ve Mutlu, 2019 & 2008-2018 yılları arası, 341 yayın & Bibliyometrik analiz \\
\hline Bu çalışma & 1970-2019 yılları arası, 680 yayın & Bibliyometrik analiz \\
\hline
\end{tabular}

Tablo 2.1'de değinilen çalışmalara ek olarak literatürde şehir lojistiğinin önemli kısımlarına odaklanan ve literatür taraması yapılan çalışmalar da bulunmaktadır. Kentsel konsolidasyon merkezi (Björklund ve Johansson, 2018; Ormond ve Telhada, 2017), kentsel yük taşımacıllğı (Visser ve diğ., 2014; Oliveira ve diğ., 2017), kentsel yolcu taşımacılığ sistemleri (Perez ve diğ., 2015), şehir lojistiği için karar destek sistemleri (Bozzo ve diğ., 2014), havaalanı merkezli planlamada şehir lojistiğinin rolü (Boloukian ve Siegmann, 2016), şehir lojistiği modelleme çalışmaları (Anand ve diğ., 2012; Anand ve di ̆.., 2015), yük taşımacıllğı modelleme (Nuzzolo ve diğ., 2013), kentsel yük taşımacılığını planlamadaki zorluklar (Lindholm ve Behrends, 2012) örnek olarak verilebilir.

\subsection{Bibliyometrik Analiz}

İlk bibliyometrik çalışma, 1917 yılında Cole ve Eales tarafından yapılmıştır. Cole ve Eales, 1550-1860 yılları arasında karşılaştırmalı anatomi alanında yayınlanan araştırmalara ilişkin istatistiksel bir analiz yapmışlardır (Lawani, 1981: 295). Bibliyometri terimi, 1969 yılında Alan Pritchard tarafından ileri sürülmüştür (Lawani, 1981: 294). Pritchard, bibliyometrinin istatistiksel bibliyografya teriminin yerini alması gerektiğini ifade etmiştir. Pritchard'a göre bibliyometri, yazılı kaynakların çeşitli yönlerini saymak ve analiz etmek yoluyla, bu kaynakların süreçlerine ve seyrine ışık tutmak için matematiğin ve istatistiksel yöntemlerin uygulanmasıdır (Lawani, 1981: 294).

Bibliyometrik analiz; ülkeler, üniversiteler, araştırma merkezleri, araştırma grupları ve dergiler özelinde akademik araştırmaların değerlendirilmesine ve analiz edilmesine imkan veren önemli bir yöntemdir. Bu yöntem ile bilimsel araştırmaların objektif kriterlere göre değerlendirilmesi mümkün olabilmektedir. Ayrıca bu yöntem, bilimsel nitelik ve üretkenliğin değerlendirilmesinde önemli bir araçtır (Martinez ve diğ., 2015: 257). Literatürde bibliyometrik analiz yönteminin kullanıldığ birçok çalışma bulunmaktadır (Donohue, 1972; Smith, 1977; Arunachalam ve Markanday, 1981; Levine, 1986; Bordons ve Barrigon, 1992; Kaminer ve Braunstein, 1998; Critchfield, 2002; Robert ve diğ., 2007; Fu ve diğ., 2010; Dong ve diğ., 2012; Zyoud ve diğ., 2014; Yu ve diğ., 2016; Erbaş1 ve diğ., 2017; Gao ve diğ., 2018; Zhu ve diğ., 2019).

\section{ARAŞTIRMANIN YÖNTEMI}

Çalı̧̧mada incelenen yayınlar, Web of Science veritabanında yer alan yayınlardan oluşmaktadır. Bu yayınlar belirlenirken, konu başlığı (topic) olarak "kent (şehir) lojistiği" terimi ölçüt alınmıştır. Aynı zamanda filtreleme alanında tüm yıllar (1970-2019) ve tüm Web of Science indeksleri (SCI-Expanded, SSCI, A\&HCI, CPCI-S, CPCI-SSH, ESCI) seçilerek 13.03.2019 tarihinde arama yapılmıştır. Bu arama sonucunda 680 makaleye ulaşılmış ve bu 680 makale örneklem olarak seçilmiştir (http://apps.webofknowledge.com, Erişim Tarihi: 13.03.2019). 
Çalışmada bibliyometrik analiz yöntemi benimsenmiş olup yayınların incelenmesinde VOSviewer programından yararlanılmıştır. İncelenen 680 yayına ilişkin yayın yılı, en çok yayın yapılan dergi/kongre, en fazla kullanılan anahtar kelime, yayın dili, en fazla yayın yapan ülke, en fazla yayın yapan araştırmacı, en fazla ortak yazarlığı olan araştırmacı, en çok atıf alan ülke, en çok atıf alan araştırmacı ve en çok atıf alan yayın bilgisi verilmiştir.

\section{BULGULAR ve YORUM}

VOSviewer programının sunmuş olduğu şekilde yer alan her bir halka, araştırmacının yinelenme sayısına göre yaptığı filtreleme sonucunda söz konusu filtre içerisinde yer alan bir öğeyi ifade etmektedir. Söz konusu bu öğe; ülke, yazar, doküman, terim vb. olabilir (Van Eck ve Waltman, 2019: 5). Halkanın büyük olmas1, şekilde yer alan öğenin yinelenme sayısının fazla olduğu anlamına gelmektedir. En büyük halka, en çok yinelenen öğedir (Van Eck ve Waltman, 2019: 9). Öğeler, yinelenme skorlarına göre tek bir renkle gösterilmekte ve gruplar halinde kümelenmektedir. Her bir öğe sadece bir kümede yer almakla birlikte herhangi bir öğenin bir kümede yer almaması da mümkün olmaktadır. Aynı zamanda öğeler arasındaki çizgiler, bağlantıları göstermektedir. Her bir bağlantının bir gücü olmaktadır. İnce bir çizgi daha zayıf bir bağlantıyı, kalın bir çizgi ise daha güçlü bir bağlantıyı ifade etmektedir (Van Eck ve Waltman, 2019: 5).

Şekil 4.1'de kent lojistiği konulu çalışmalarda kullanılan anahtar kelimeler verilmiştir. İncelenen yayınlarda toplam 1671 anahtar kelime elde edilmiştir. Bu anahtar kelimelerden en az 5 kez yinelenmiş olan 55 anahtar kelimeye ulaşılmıştır. Bu 55 kelimeden ise konu ile ilgisi olmadığı düşünülen "its" kelimesi çıkarılmıştır. Şekil incelendiğinde; en fazla kullanılan anahtar kelimenin "city logistics" olduğu görülmektedir. Bu anahtar kelime toplamda 364 kez kullanılmıştır. En fazla kullanılan ikinci anahtar kelime, 71 kez kullanılmış olan "urban freight transport" kelimesidir. Bu iki anahtar kelimeyi sirasiyla "urban freight" (37 kez), "vehicle routing" (36 kez), "urban logistics" (26 kez), "sustainability" (24 kez), "simulation" (19 kez), "logistics" (18 kez) ve "freight transport" (15 kez) anahtar kelimeleri takip etmektedir. Ayrıca anahtar kelimeler, 8 kümeye ayrılmıştır. Her bir renk, bir kümeyi ifade etmektedir.

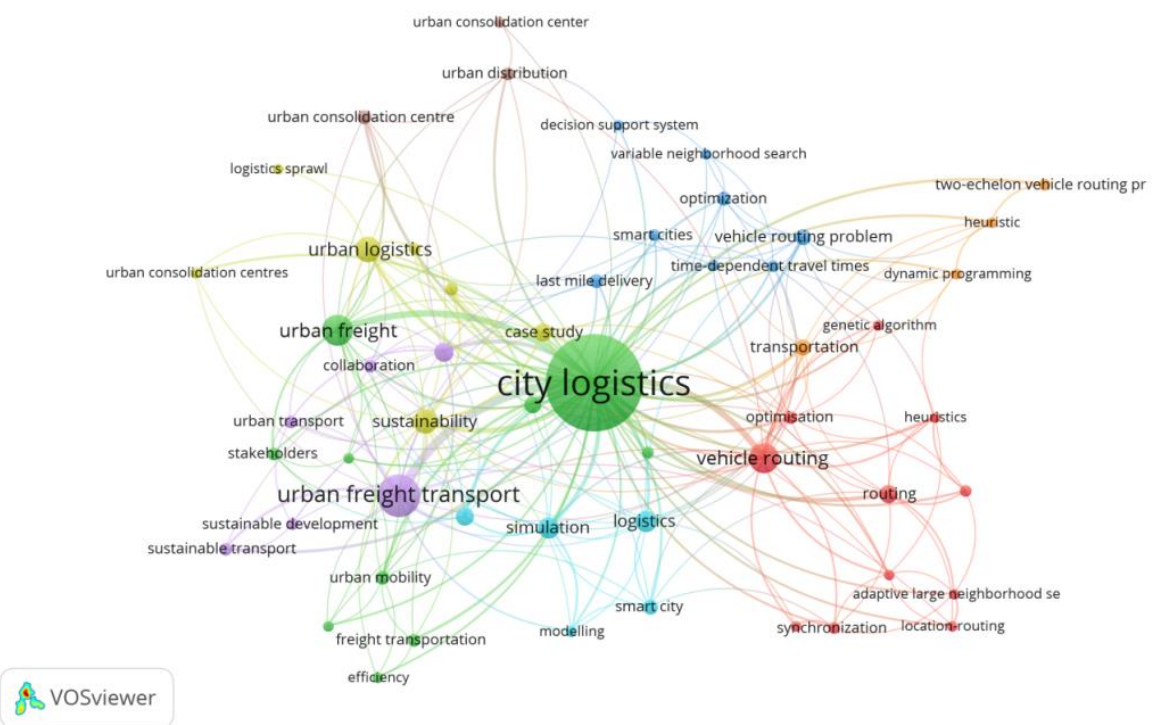

Şekil 4.1 En Fazla Kullanılan Anahtar Kelimeler

Şekil 4.2'de en fazla ortak yazarlığı olan araştırmacılar verilmiştir. İncelenen yayınlarda toplam 1277 araştırmacı olduğu görülmüştür. Bu araştırmacılardan yayın ve atıf sayısı en az 5 olan 47 araştırmacı dikkate alınmıştır. Şekilde araştırmacı isimlerinin yer aldığı alanın rengi ortak yazarlık sayısına göre farklılık göstermektedir. Mavi renk az sayıda ortak yazarlığı ifade ederken sarı renk daha fazla sayıda ortak yazarlığı ifade etmektedir. Şekil incelendiğinde; en fazla ortak yazarlığı olan araştırmacının Eiichi Taniguchi (26 ortak yazarlık) olduğu görülmektedir. Bu araştırmacıyı sırasıyla Antonio Comi (18 ortak yazarlık) ve T. Gabriel Crainic (17 ortak yazarlık) izlemektedir. 


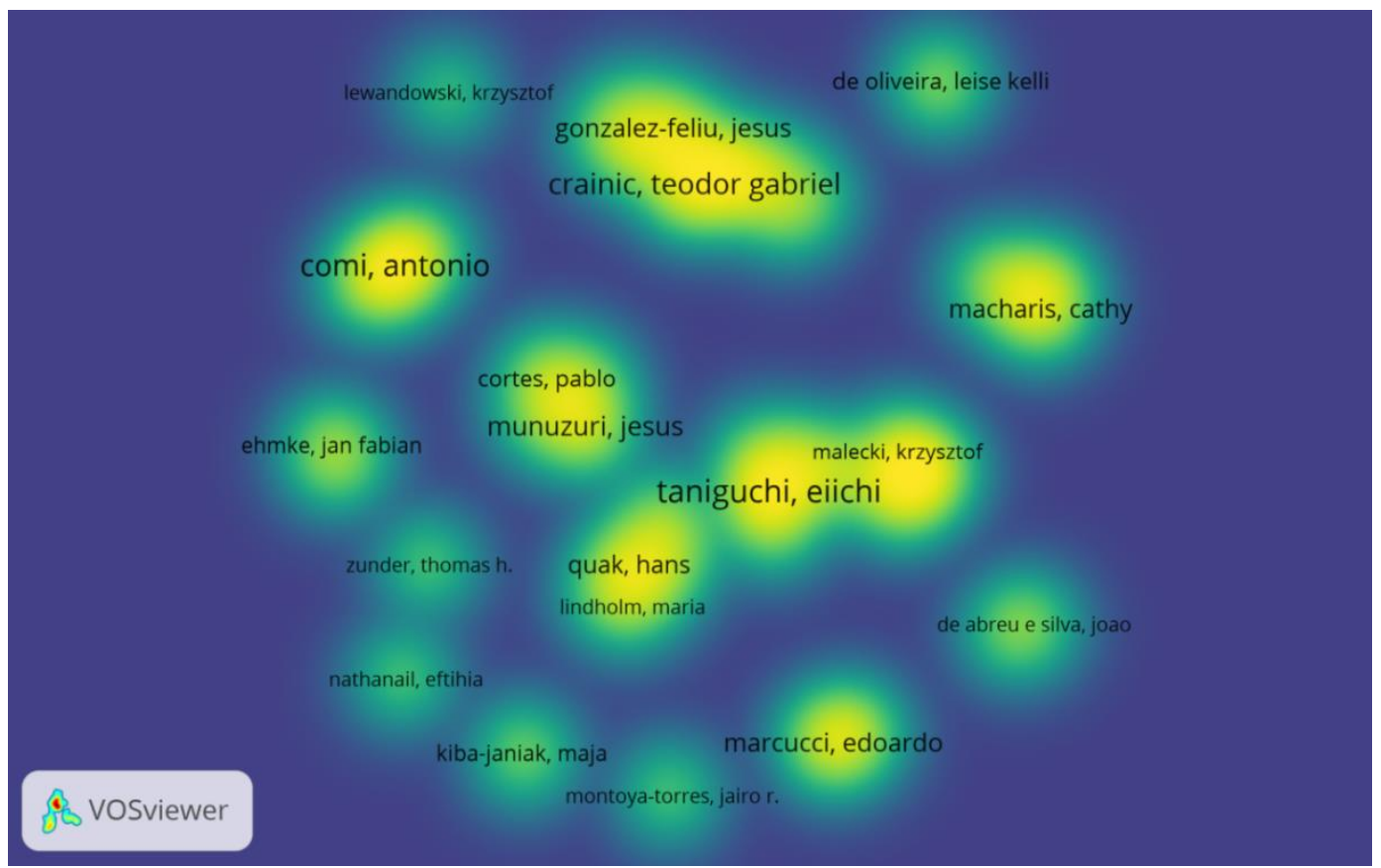

Şekil 4.2 En Fazla Ortak Yazarlığı Olan Araştırmacılar

Şekil 4.3'te en fazla yayın yapan ülkeler verilmiştir. İncelenen yayınlarda toplam 56 ülke olduğu görülmüsstür. Bu ülkelerden yayın sayısı en az 5 olan 28 ülke dikkate alınmıştır. Şekil incelendiğinde; en fazla yayının İtalya'da (97 yayın) yapıldığı görülmektedir. İtalya'yı sırasıyla Çin Halk Cumhuriyeti (90 yayın), Polonya (64 yayın), Fransa (60 yayın), Kanada (46 yayın), ABD (43 yayın), Almanya (43 yayın) ve Japonya (39 yayın) takip etmektedir. Ayrıca ülkeler arasında kümelenmeler olduğu görülmektedir. Örneğin; Kanada, Çin Halk Cumhuriyeti, ABD, Almanya, Avusturya, Güney Kore, Portekiz ve Singapur'un aynı kümede yer aldığı anlaşılmaktadır.

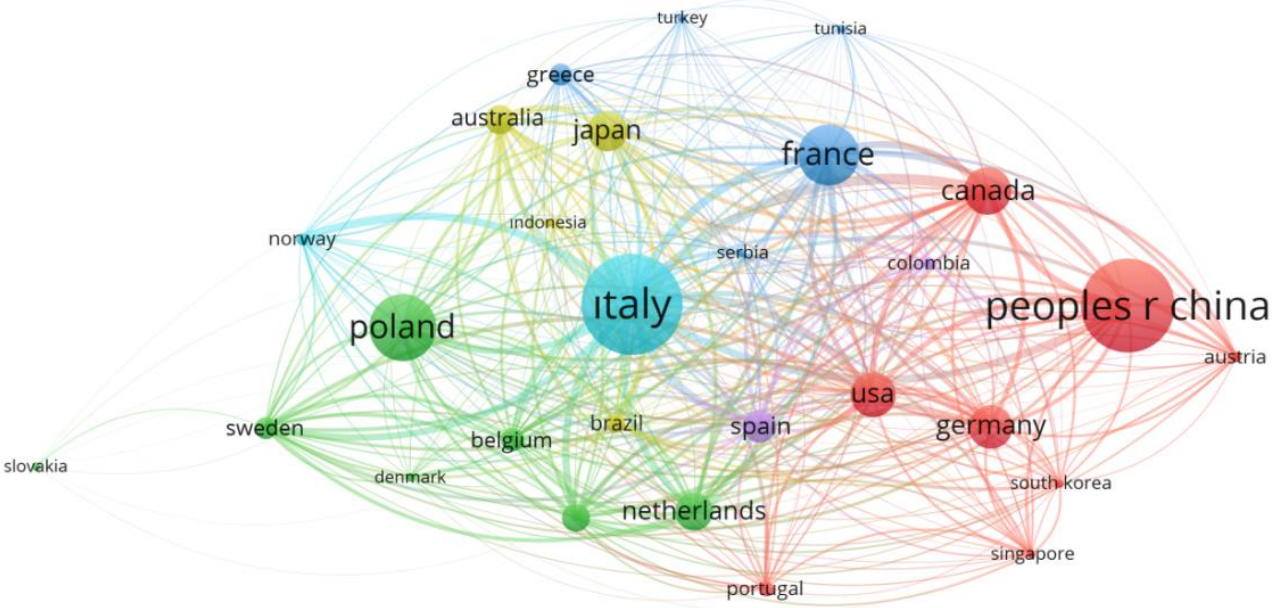

VOSviewer

\section{Şekil 4.3 En Fazla Yayın Yapan Ülkeler}

Şekil 4.4'te en fazla yayın yapan araştırmacılar gösterilmiştir. Bu araştırmacılardan yayın sayısı en az 5 olan 48 araştırmacı dikkate alınmıştır. Şekil incelendiğinde; en fazla yayın yapan araştırmacının Eiichi 
Taniguchi (27 yayın) olduğu anlaşılmaktadır. Bu araştırmacıyı sırasıyla Stanislaw Iwan (19 yayın), Antonio Comi (18 yayın), T. Gabriel Crainic (18 yayın), Guido Perboli (14 yayın) ve Jesus Munuzuri (14 yayın) takip etmektedir. Ayrıca şekilde; araştırmacıların oluşturmuş olduğu kümelenmeler ve araştırmacılar arasındaki bağlantılar gösterilmiştir.

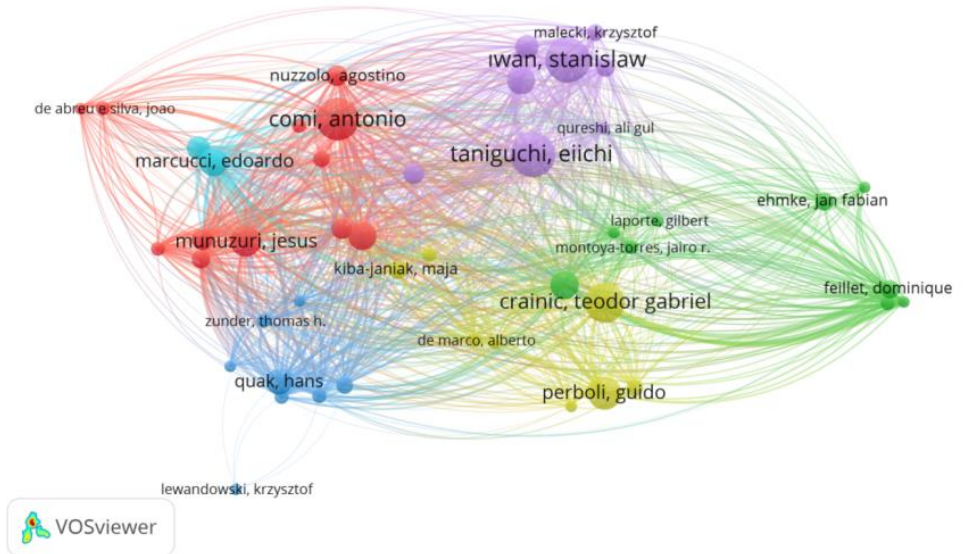

\section{Şekil 4.4 En Fazla Yayın Yapan Araştırmacılar}

Şekil 4.5 'te en fazla atıf alan ülkeler verilmiştir. İncelenen yayınlarda toplam 56 ülke olduğu görülmüştür. Bu ülkelerden yayın ve atıf sayısı en az 5 olan 27 ülke dikkate alınmıştır. Şekil incelendiğinde; en fazla atıf alan ülkenin İtalya (1337 atıf) olduğu görülmektedir. İtalya'yı sırasıyla Kanada (1107 atıf), Fransa (589 atıf), Japonya (777 at1f), Hollanda (750 atıf), ABD (422 atıf), Avustralya (387 at1f) ve İspanya (379 atıf) izlemektedir. Ayrıca ülkeler arasında kümelenmeler ve bağlantılar olduğu görülmektedir. Örneğin; İsveç, İspanya, Yunanistan, Güney Kore, Kolombiya ve Sırbistan'ın aynı kümede yer aldığı anlaşılmaktadır.

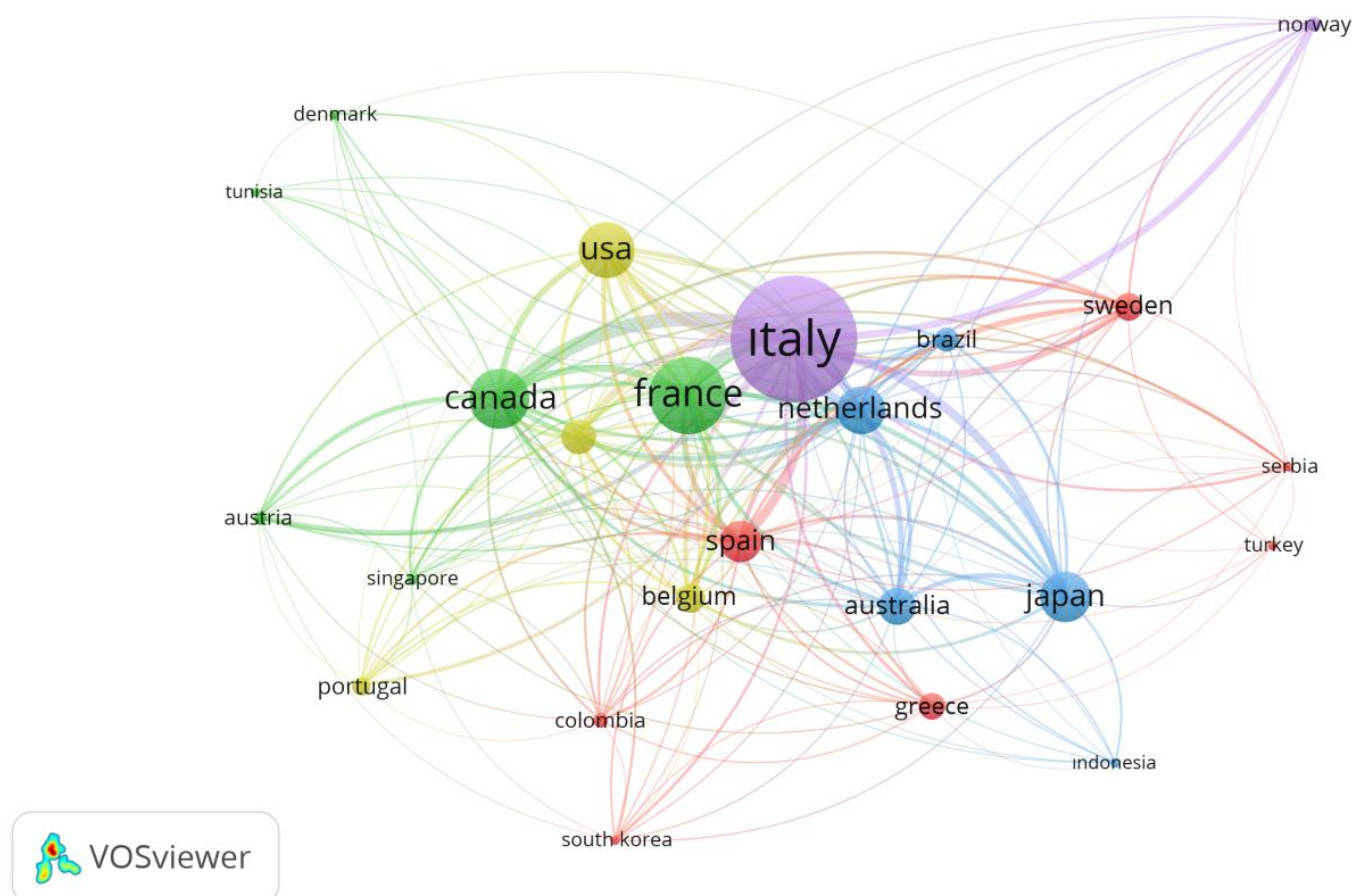

Şekil 4.5 En Fazla Atıf Alan Ülkeler

Şekil 4.6'da en fazla atıf alan araştırmacılar verilmiştir. Bu araştırmacılardan yayın ve atıf sayısı en az 5 olan 47 araştırmacı dikkate alınmıştır. Şekil incelendiğinde; en fazla atıf alan araştırmacının Eiichi Taniguchi (592 atıf) olduğu görülmektedir. Bu araştırmacıyı sırasıyla T. Gabriel Crainic (352 atıf), Antonio Comi (303 atıf), Laetitia Dablanc (273 atıf), Guido Perboli (242 atıf), Edoardo Marcucci (241 atıf) ve Jesus GonzalezFeliu (207 atıf) takip etmektedir. 


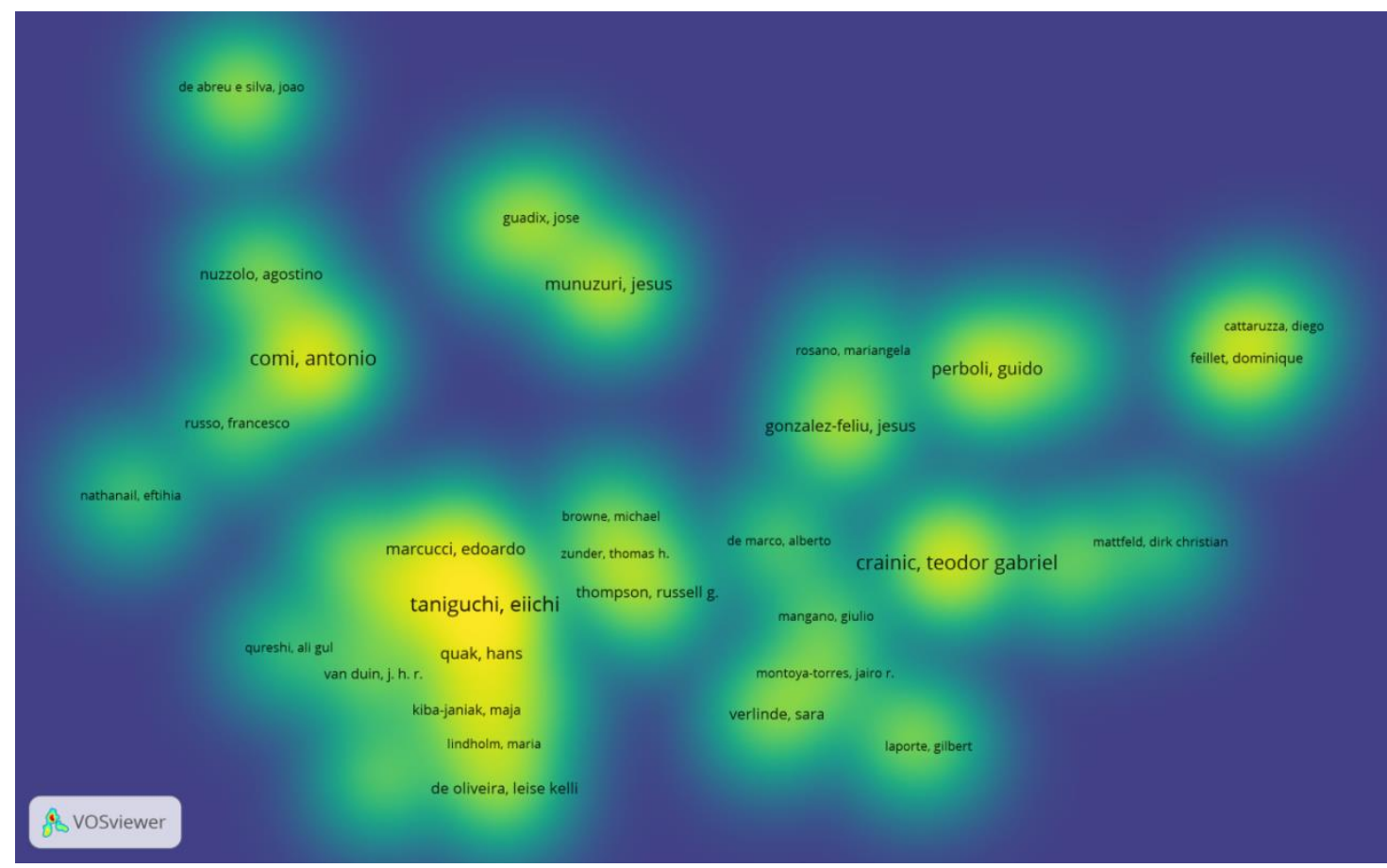

Şekil 4.6 En Fazla Atıf Alan Araştırmacılar

Şekil 4.7'de en fazla atıf alan yayınlar gösterilmiştir. İncelenen toplam 680 yayından atıf sayısı en az 5 olan 254 yayına ulaşılmış olup bu yayınlardan 231'i dikkate alınmıştır. Şekil incelendiğinde; en fazla atıf alan yayının Dablanc (2007, 182 atıf) olduğu görülmektedir. Bu yayını sırasıyla Crainic vd., (2009a, 169 atıf), Crainic vd., (2004, 153 atıf), Munuzuri vd., (2005, 140 atıf), Hemmelmayr vd., (2012, 115 atıf), Crainic vd., (2009, 104 atıf), Perboli vd., (2011, 104 atıf), Taniguchi ve Shimamoto (2004, 101 atıf), Ando ve Taniguchi (2006, 86 atıf) ve Taniguchi ve Heijden (2000, 86 atıf) izlemektedir.

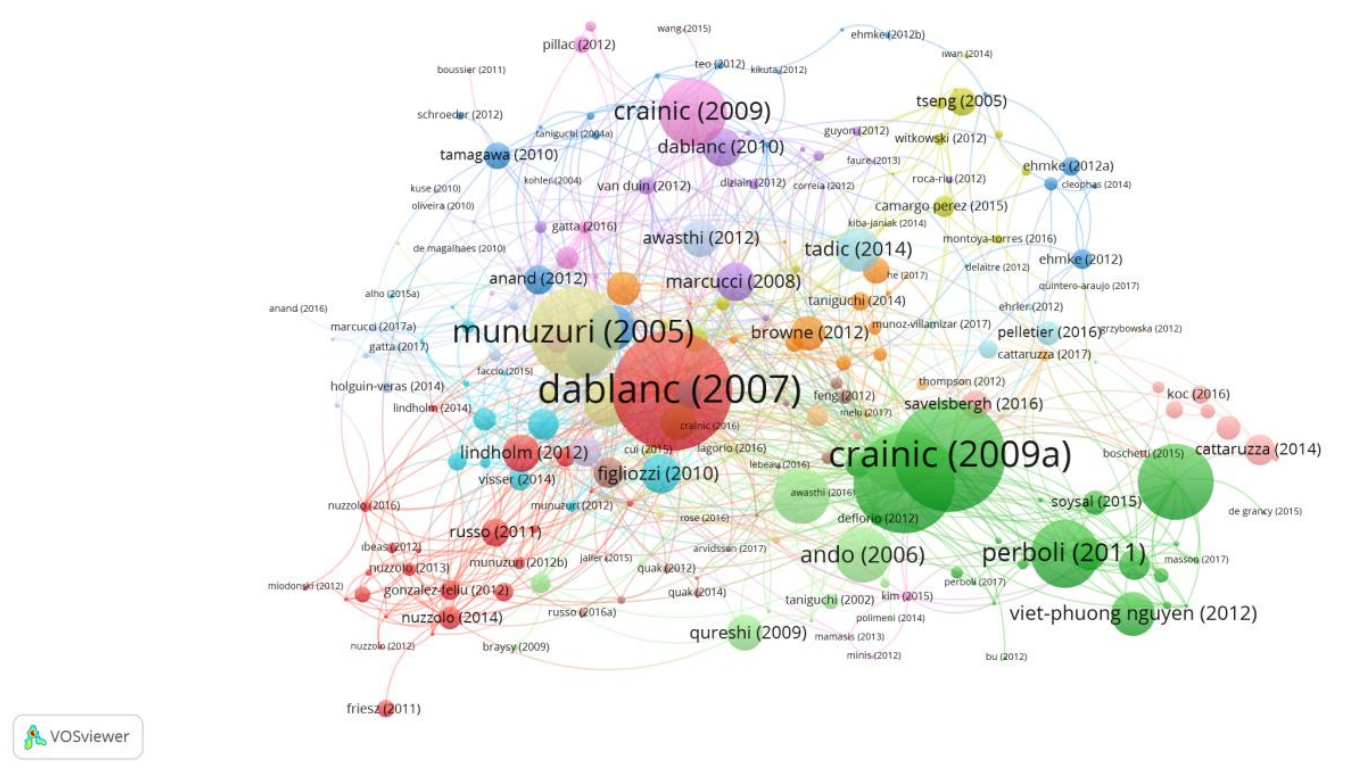

\section{Şekil 4.7 En Fazla Atıf Alan Yayınlar}

Şekil 4.8'de yayın yapılan yıllar ve bu yıllardaki yayın sayıları gösterilmiştir. Şekil incelendiğinde; en fazla yayının 2016 yılında yapıldığ görülmektedir. 2011, 2005, 2006, 2007, 2008 yıllarında 16'dan daha az sayıda yayın yapıldığ 1 anlaşılmaktadır. 2016 yılından sonra yıllar itibariyle yapılan yayın sayısının azaldığı görülmektedir. Ayrıca kent lojistiği literatürüne ilişkin olarak yıllar bazında herhangi bir artış veya azalış 
trendinin olmadığını söylemek yanlış olmayacaktır. 2019 yılı yayın sayısı, 01.01.2019-13.03.2019 tarihleri arasında yayınlanmış olan yayınların sayısıdır.

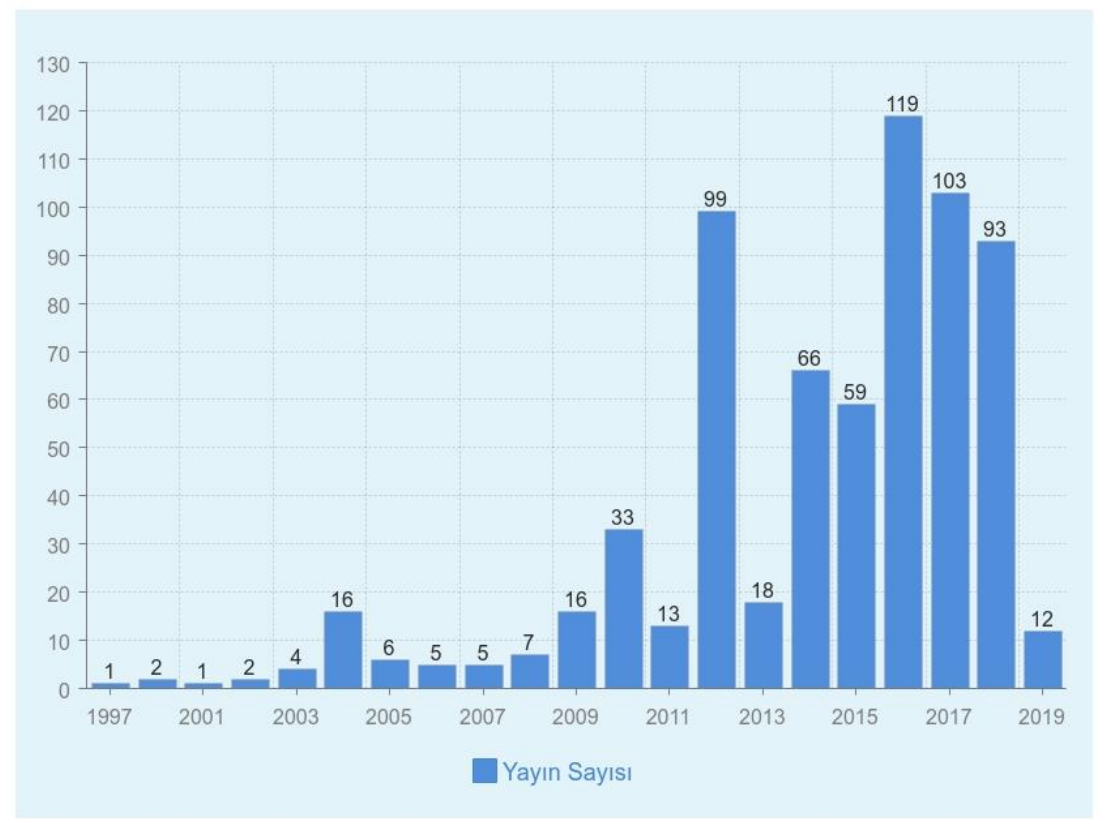

Şekil 4.8 Yayın Yılları

Tablo 4.1'de en fazla yayın yapılan 10 dergi/kongre gösterilmiştir. Tablo incelendiğinde; en fazla yayının Procedia Social and Behavioral Sciences'ta yapıldığı görülmektedir. En fazla yayın yapılan 10 dergi/kongre'den 4'ünün International Conference on City Logistics kongresine ilişkin olduğu anlaşılmaktadır.

Tablo 4.1 En Fazla Yayın Yapılan 10 Dergi/Kongre

\begin{tabular}{cc}
\hline Dergi/Kongre & Yayın Sayısı \\
\hline Procedia Social and Behavioral Sciences & 126 \\
Transportation Research Procedia & 76 \\
Seventh International Conference on City Logistics & 66 \\
Ninth International Conference on City Logistics & 32 \\
6th International Conference on City Logistics & 18 \\
Eighth International Conference on City Logistics & 18 \\
2nd Int. Conf. Green Cit. Green Log. For Greener Cities & 16 \\
Sustainability & 13 \\
European Journal of Operational Research & 12 \\
Logistics Systems For Sustainable Cities & 12 \\
\hline
\end{tabular}

Şekil 4.9'da yayın dillerine ilişkin bilgiler sunulmuştur. Şekil incelendiğinde; yayınlarda İngilizce, Çince, İspanyolca, Portekizce ve Slovakça olmak üzere beş farklı dil kullanıldığ görülmektedir. Bununla birlikte yayınların neredeyse tamamının İngilizce yazıldığı anlaşılmaktadır. 


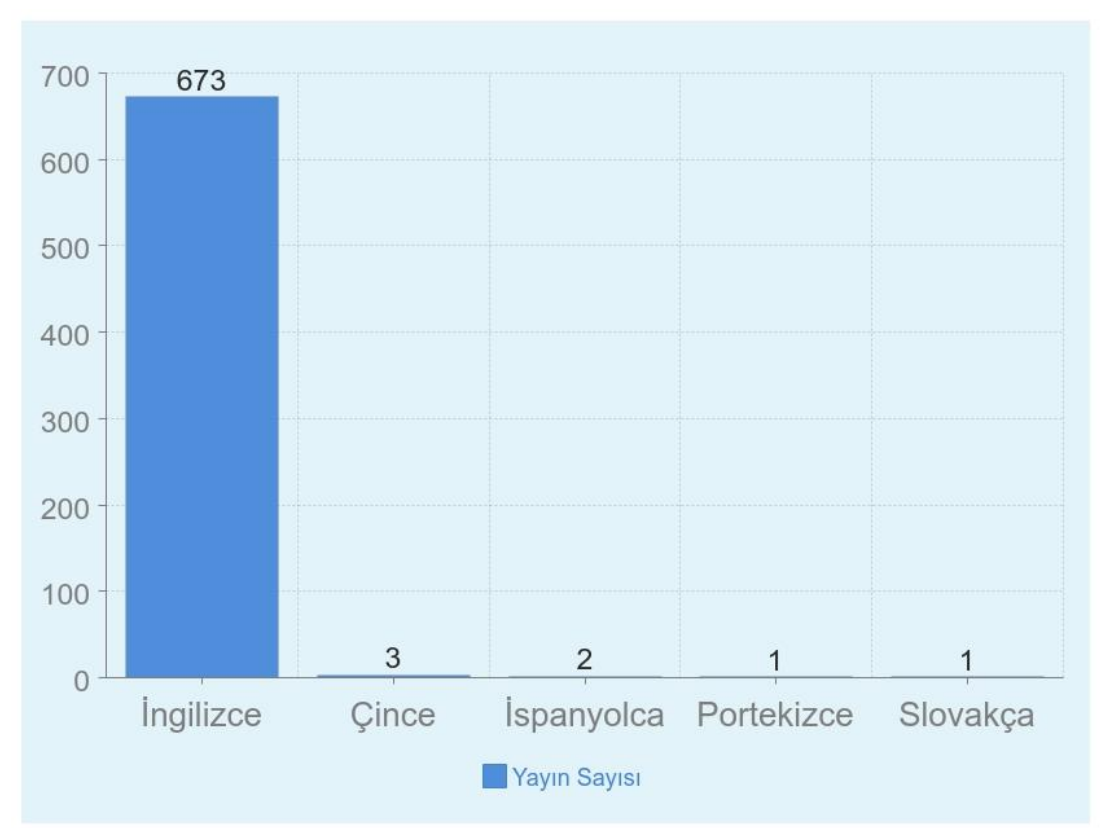

Şekil 4.9 Yayın Dilleri

\section{SONUÇ ve ÖNERILER}

Şehir lojistiği, gelişmiş kentsel yük taşımacıllı̆ı sistemlerinin optimizasyonunu ifade etmektedir. Şehir lojistiğinde yerine getirilmesi gereken temel faaliyet, şehir dağıtım merkezleri gibi konsolidasyon tesisleri aracılığıyla birçok farklı nakliyeci-taşıyıcı-alıcı arasında gerçekleşen ticari ilişkilerin koordine edilmesidir (Crainic, 2008: 207). Şehir lojistiği; verimli, çevre dostu ve güvenli kentsel yük taşıma sistemleri sunarak sürdürülebilir ve yaşanabilir şehirler oluşturma adına büyük önem arz etmektedir (Taniguchi, 2015: 57). Zamanla hava kirliliğii, gürültü ve güvenli ulaşım gibi küresel ve yerel çevresel problemlere ilişkin kaygıların artması şehir lojistiğine verilen önemi daha da arttırmıştır (Taniguchi, 2015: 49). Söz konusu bu artışa benzer bir şekilde şehir lojistiğine ilişkin yapılan araştırmaların sayısı her yıl katlanarak artmaktadır. Bu durum şehir lojistiği olgusuna gösterilen ilginin önemli ölçüde arttığını ortaya koymaktadır (Lagorio ve diğ., 2016: 925). Dolayısıyla bu çalışma ile 1970-2019 yılları arasında şehir lojistiği alanında yapılan araştırmaları incelemek ve akademik yazında şehir lojistiğine ilişkin araştırmaların hangi doğrultuda ilerlediğini ortaya koymak amaçlanmıştır. $\mathrm{Bu}$ doğrultuda bulguların elde edilmesi sürecinde bibliyometrik analiz yönteminden yararlanılmıştır.

Yapılan bibliyometrik analiz sonucunda elde edilen önemli bulguları şu şekilde özetlemek mümkündür:

$>$ En fazla kullanılan anahtar kelime "şehir lojistiği"dir. En fazla kullanılan ikinci anahtar kelime ise "kentsel yük taşımacılığı" kavramıdır.

$>$ En fazla ortak yazarlığı olan, en fazla yayın yapan ve en fazla atıf alan araştırmacı E. Taniguchi'dir.

$>$ En fazla yayın yapan ve en fazla atıf alan ülke İtalya'dır.

$>$ En fazla atıf alan yayın, Dablanc tarafından 2007 yılında kaleme alınan yayındır.

$>$ En fazla yayın 2016 yılında yapılmıştır.

$>$ En fazla yayın Procedia Social and Behavioral Sciences dergisinde yapılmıştır.

$>$ Yayınların tamamına yakınının yazım dili İngilizce'dir.

Çalışmanın bazı sınırlılıkları bulunmaktadır. Bunlar; çalışmada bulguların elde edildiği 680 makaleye 13.03.2019 tarihinde yapılan tarama sonucunda ulaşılmıştır. Sonraki günlerde veritabanına eklenen yeni yayınlar ile birlikte söz konusu makalelere ilişkin atıf sayısı, yayın dili, yayın yapan ülke, özetlerde yer alan kelimeler ve bu kelimelerin sayısı farklı1ık gösterebilecek dolayısıyla farklı bulguların elde edilmesi mümkün olabilecektir. Sonraki çalışmalarda araştırmacılar, şehir lojistiği yazınının bir bölümünü (örneğin; son beş yı1 gibi) dikkate alarak bibiliyometrik analiz yöntemini kullanabilirler. Aynı zamanda farklı analiz yöntemlerini (sistematik literatür taraması, içerik analizi gibi) kullanarak da söz konusu literatürün tamamına veya bir bölümüne ilişkin analizler yapabilirler. 


\section{KAYNAKLAR}

Anand, N., Quak, H., van Duin, R. ve Tavasszy, L. (2012). City logistics modeling efforts: Trends and gaps-A review. Procedia-Social and Behavioral Sciences, 39, 101-115.

Anand, N., Van Duin, R., Quak, H. ve Tavasszy, L. (2015). Relevance of city logistics modelling efforts: a review. Transport Reviews, 35(6), 701-719.

Ando, N. ve Taniguchi, E. (2006). Travel time reliability in vehicle routing and scheduling with time windows. Networks and spatial economics, 6(3-4), 293-311.

Arunachalam, S. ve Markanday, S. (1981). Science in the middle-level countries: a bibliometric analysis of scientific journals of Australia, Canada, India and Israel. Journal of Information Science, 3(1), 13-26.

Behrends, S. (2016). Recent developments in urban logistics research-a review of the proceedings of the international conference on city logistics 2009-2013. Transportation Research Procedia, 12, 278-287.

Björklund, M. ve Johansson, H. (2018). Urban consolidation centre-a literature review, categorisation, and a future research agenda. International Journal of Physical Distribution \& Logistics Management, 48(8), 745-764.

Boloukian, R. ve Siegmann, J. (2016). Urban logistics; a key for the airport-centric development-A review on development approaches and the role of urban logistics in comprehensive airport-centric planning. Transportation Research Procedia, 12, 800-811.

Bordons, M. ve Barrigón, S. (1992). Bibliometric analysis of publications of Spanish pharmacologists in the SCI (198489). Part II. Scientometrics, 25(3), 425-446.

Bozzo, R., Conca, A. ve Marangon, F. (2014). Decision support system for city logistics: literature review, and guidelines for an ex-ante model. Transportation Research Procedia, 3, 518-527.

Cole, F. J. ve Eales, N. B. (1917). The History of Comparative Anatomy. Part I: A Statistical Analysis ofthe Literature. Science Progress, 11, 578-596.

Crainic, T. G. (2008). City logistics. In State-of-the-Art Decision-Making Tools in the Information-Intensive Age. INFORMS, 181-212.

Crainic, T. G., Gendreau, M. ve Potvin, J. Y. (2009). Intelligent freight-transportation systems: Assessment and the contribution of operations research. Transportation Research Part C: Emerging Technologies, 17(6), 541-557.

Crainic, T. G., Ricciardi, N. ve Storchi, G. (2004). Advanced freight transportation systems for congested urban areas. Transportation Research Part C: Emerging Technologies, 12(2), 119-137.

Crainic, T. G., Ricciardi, N. ve Storchi, G. (2009a). Models for evaluating and planning city logistics systems. Transportation science, 43(4), 432-454.

Critchfield, T. S. (2002). Evaluating the function of applied behavior analysis: A bibliometric analysis. Journal of Applied Behavior Analysis, 35(4), 423-426.

Dablanc, L. (2007). Goods transport in large European cities: Difficult to organize, difficult to modernize. Transportation Research Part A: Policy and Practice, 41(3), 280-285.

Dong, B., Xu, G., Luo, X., Cai, Y. ve Gao, W. (2012). A bibliometric analysis of solar power research from 1991 to 2010. Scientometrics, 93(3), 1101-1117.

Donohue, J. C. (1972). A bibliometric analysis of certain information science literature. Journal of the American Society for Information Science, 23(5), 313-317.

Erbaşı, A., Cabi, A., Gümrah, A. ve Hakses, H. (2017). Selçuk Üniversitesi Sosyal Bilimler Meslek Yüksekokulu Dergisi’nin Bibliyometrik Analizi. Selçuk Üniversitesi Sosyal Bilimler Meslek Yüksekokulu Dergisi, 20(2), 206214.

Fu, H. Z., Ho, Y. S., Sui, Y. M. ve Li, Z. S. (2010). A bibliometric analysis of solid waste research during the period 1993-2008. Waste Management, 30(12), 2410-2417.

Gao, H., Huang, F. Y. ve Wang, Z. P. (2018). Research Trends of Macrophage Polarization: A Bibliometric Analysis. Chinese Medical Journal, 131(24), 2968-2975.

Hajduk, S. (2017). Bibliometric analysis of publications on city logistics in international scientific literature. Procedia Engineering, 182, 282-290.

Hemmelmayr, V. C., Cordeau, J. F. ve Crainic, T. G. (2012). An adaptive large neighborhood search heuristic for twoechelon vehicle routing problems arising in city logistics. Computers \& operations research, 39(12), 3215-3228.

Hu, W., Dong, J., Hwang, B. G., Ren, R. ve Chen, Z. (2019). A Scientometrics Review on City Logistics Literature: Research Trends, Advanced Theory and Practice. Sustainability, 11(10), 2724.

Kaminer, N. ve Braunstein, Y. M. (1998). Bibliometric analysis of the impact of Internet use on scholarly productivity. Journal of the American Society for Information Science, 49(8), 720-730.

Kaur, R. ve Awasthi, A. (2018). City logistics: a review and bibliometric analysis. International Journal of Bibliometrics in Business and Management, 1(2), 160-188.

Lagorio, A., Pinto, R. ve Golini, R. (2016). Research in urban logistics: a systematic literature review. International Journal of Physical Distribution \& Logistics Management, 46(10), 908-931.

Lawani, S. M. (1981). Bibliometrics: its theoretical foundations, methods and applications. Libri, 31(1), 294-315.

Levine, L. O. (1986). Prolific inventors-A bibliometric analysis. Scientometrics, 10(1-2), 35-42.

Lindholm, M. ve Behrends, S. (2012). Challenges in urban freight transport planning-a review in the Baltic Sea Region. Journal of Transport Geography, 22, 129-136. 
Lindholm, M. (2013). Urban freight transport from a local authority perspective-a literature review. European Transport, 54, 1-37.

Martínez, M. A., Cobo, M. J., Herrera, M. ve Herrera-Viedma, E. (2015). Analyzing the scientific evolution of social work using science mapping. Research on Social Work Practice, 25(2), 257-277.

Muñuzuri, J., Larrañeta, J., Onieva, L. ve Cortés, P. (2005). Solutions applicable by local administrations for urban logistics improvement. Cities, 22(1), 15-28.

Neghabadi, P. D., Samuel, K. E. ve Espinouse, M. L. (2016). City logistics: a review and research framework. In RIRL 2016 EPFL.

Neghabadi, D. P., Samuel, E. K. ve Espinouse, M. L. (2019). Systematic literature review on city logistics: overview, classification and analysis. International Journal of Production Research, 57(3), 865-887.

Nuzzolo, A., Coppola, P. ve Comi, A. (2013). Freight transport modeling: review and future challenges. International Journal of Transport Economics, 40(2), 151-181.

Oliveira, C., Albergaria De Mello Bandeira, R., Vasconcelos Goes, G., Schmitz Gonçalves, D. ve D’Agosto, M. (2017). Sustainable vehicles-based alternatives in last mile distribution of urban freight transport: A systematic literature review. Sustainability, 9(8), 1324.

Ormond, P. ve Telhada, J. (2017). Using Urban Consolidation Centre With Cycloscargos Support To Increase The Performance And Sustainability Of Urban Logistics: A Literature Review And A Case Study In The City Of São Paulo. 3rd International Conference on Energy and Environment: bringing together Engineering and Economics, 29-30 June, Porto, Portugal.

Perboli, G., Tadei, R. ve Vigo, D. (2011). The two-echelon capacitated vehicle routing problem: Models and math-based heuristics. Transportation Science, 45(3), 364-380.

Pérez, J. C., Carrillo, M. H. ve Montoya-Torres, J. R. (2015). Multi-criteria approaches for urban passenger transport systems: a literature review. Annals of operations research, 226(1), 69-87.

Robert, C., Wilson, C. S., Gaudy, J. F. ve Arreto, C. D. (2007). The evolution of the sleep science literature over 30 years: A bibliometric analysis. Scientometrics, 73(2), 231-256.

Savrun, B. ve Mutlu, H. M. (2019). Kent Lojistiği Üzerine Bibliyometrik Analiz. Kent Akademisi, 12(2), $364-386$.

Smith, G. M. (1977). Key Books in business and management studies: a bibliometric analysis. Aslib Proceedings 29(5), 174-188.

Taniguchi, E. ve Shimamoto, H. (2004). Intelligent transportation system based dynamic vehicle routing and scheduling with variable travel times. Transportation Research Part C: Emerging Technologies, 12(3-4), 235-250.

Taniguchi, E. ve Van Der Heijden, R. E. (2000). An evaluation methodology for city logistics. Transport Reviews, 20(1), 65-90.

Taniguchi, E., Thompson, R. G., Yamada, T. ve Van Duin, R. (2001). City Logistics: Network Modelling and Intelligent Transport Systems. Amsterdam: Pergamon.

Taniguchi, E. (2015). Green Logistics and Transportation. Greening of Industry Networks Studies 4 (B. Fahimna vd., ed.), Switzerland.

Van Eck, N. J. ve Waltman, L. (2019). VOSviewer Manual. Universiteit Leiden.

Visser, J., Nemoto, T. ve Browne, M. (2014). Home delivery and the impacts on urban freight transport: A review. Procedia-social and behavioral sciences, 125, 15-27.

Yu, H., Wei, Y. M., Tang, B. J., Mi, Z. ve Pan, S. Y. (2016). Assessment on the research trend of low-carbon energy technology investment: A bibliometric analysis. Applied energy, 184, 960-970.

Zhu, S., Jin, W. ve He, C. (2019). On evolutionary economic geography: a literature review using bibliometric analysis. European Planning Studies, 27(4), 639-660.

Zyoud, S. H., Al-Jabi, S. W., Sweileh, W. M. ve Awang, R. (2014). A bibliometric analysis of research productivity of Malaysian publications in leading toxicology journals during a 10-year period (2003-2012). Human \& experimental toxicology, 33(12), 1284-1293.

Wolpert, S. ve Reuter, C. (2012). Status quo of city logistics in scientific literature: systematic review. Transportation Research Record: Journal of the Transportation Research Board, (2269), 110-116.

http://apps.webofknowledge.com/Search.do?product=WOS\&SID=D1gKVXfiLMzsVi4kQfJ\&search_mode=GeneralSe arch\&prID=6f641400-6b24-4cd8-a3ab-2d83a9e0b008, (Erişim Tarihi: 13.03.2019).

https://population.un.org/wup/Publications/Files/WUP2018-PressRelease.pdf, (Erişim Tarihi: 25.03.2019). 